\title{
EFFECTS OF GLOBALIZATION ON HUMAN RESOURCE DEVELOPMENT AND MANAGEMENT IN INDIA
}

\author{
Dr. C K GOMATHY, Mr. V.VAMSI, Mr. YALAVARTHY JEEVAN KUMAR, Mr K. JITIN PRAGNISH \\ Sri Chandrasekharendra Saraswathi Viswa Mahavidyalaya , Kanchipuram
}

\section{ABSTRACT}

In India the economy and society are undergoing changes due to globalization. This paper examines the effect of globalization on human resource development and management in India. Conceptual analysis of globalization was explained in different dimensions. Three basic models and approaches in understanding the dynamics and growing influence of globalization especially in developing countries were briefly discussed. The problems of globalization were also highlighted. Furthermore, the concept of human resource management was viewed as an overall importance of human to development. Lastly, four models and strategic approaches which included ethnocentric, polycentric, geocentric and regioncentric were explained. Globalization on human resource development was viewed from the perspective of organizational and workplace learning and knowledge and technology transport. Based on this, the paper concluded with feasible recommendations based on the conclusion.

Keywords: Globalization, Human Resource Development, Management and IndiaTalent

\section{BACKGROUND TO THE STUDY}

The concept and significance of globalization is increasingly becoming broader and therefore no longer strictly limited to the issues of trading and business activities. It has become connected with information and communication networks, trade, cultures, environmental initiatives, political actions, practices, polices as well as military forces across borders (Marquardt, 1991). Also, in the globalized economy, the production value of commodities, the growth of enterprises and even the enhancement of national competitiveness are dependent on the knowledge and mastery of human resources.

Globalization in its intrinsic nature is continuously impacting on human resource management and development in terms of adapting to varying socioeconomic changes and challenges. Furthermore, globalization continue to ensure that economic and social forces, interests and commitments, values and tastes, challenges and opportunities are interconnected in a special way. The concept of human resource development encompasses both a narrow view of skill and knowledge acquisition for employment to a broader perspective of human development for the well-being of individuals and society at large (Rao, 1996). Human resources are the life blood of an organization. It is the most relevant and adaptive resources of the organization (Anyim, Ikemefuna and Mbah, 2011). In this context, this paper conceptually analyses the effect of globalization on human resource development and management in India. Thus, it is important to underscore the fact that globalization is not just an economic phenomenon because it affects all aspects of life. Concept and Views of Globalization Levitt (1983) viewed global change as an economic concept, seeing it rather as one world market rather than one world production system. He was one of 
the first to the term globalization to stress the convergence of world markets, to sell the same things in the same way everywhere which would combine marketing and standardization of production. As an economic phenomenon, globalization is visible in the transition from distinct national economies towards a single global economy. According to Onodugo (2012), there exist a huge body of literature on the subject of globalization and it's attendant implications on the socio-economic and political welfare of nation states. The term has different facets, mostly seen in terms of economic and technological forces with huge effects on both the social and political sphere. Various attempts at straight definitions include; the process (or a set of processes) which embodies a transformation in the spatial organization of social relations and transactions assessed in terms of their extensity, intensity velocity and impact generating transcontinental or interregional flows and networks of activity, interaction and exercise of power (Held et al., 1991). This implies that globalization is a process not a static condition. Globalization is also defined as the closer integration of the countries and peoples of the world which have been brought about by substantial reduction of costs of transportation and communication and the breakdown of artificial barriers to the flows of goods, services, capital, knowledge and people across borders (Stiglitz, 2006).

\section{INFLUENCE OF GLOBALIZATION}

Essentially, globalization refers to the increasing integration of national economies in terms of trade, financial flows, ideas, information and technology. Globalization has increased the ratio of trade to GDP for many countries and caused a sustained increase in capital flows between countries and an increase in trade in goods and services. It has brought diminishing national borders and the fusing of individual national markets. The rise of the internet and recent advances in telecommunications has boosted globalization. Models and Problems of Globalization Tickly (2001) opined that there are three basic models and approaches in understanding the dynamics and growing influence of globalization especially in developing countries.

1 Hyper-globalistic Approach The central idea of this approach is that we are entering into a truly global age with distinctively new forms of global culture, governance and civil society. The believe is that this new state will overrun and supplement the national education and culture, with traditional schooling methods giving way to virtual and high tech learning methods. However most critics dismiss this postulation as being preposterous (Kenway,1996).

2 The skeptical Approach This view believes that global capitalism has led to greater polarization between the developed and developing countries hence there is a need for nation states to respond in the direction of more controls to stem the tide of the consequences of globalized economy (Onodugo, 2012).

3 The Transformationlistic Approach The proponents of this view believe that the world is indeed experiencing an unprecedented level of global interconnectedness, with a rearrangement in the poverty-wealth divide. This approach suggests a shift from national groupings to international ethnicities across nations and from a fixed to fluid cultural boundaries. Globalization has it problems among which are the following: 
a A strong coalition of environmentalists, antipoverty campaigners, trade unionists and anticapitalist groups see the growth of global companies as raising more problems that it solves.

b Joining the world economy means low developing countries are exposed to external economic forces over which they little control. c Reduced national sovereignty making macroeconomic management by domestic government difficult.

4 A state's ability to raise corporation taxation is declining especially transnational companies which may relocate to avoid paying domestic taxes through transfer pricing and; 5 Globalization may be strengthening the position of the developed economies that are better able to take advantage of free trade.

\section{CONCEPT OF HUMAN RESOURCE DEVELOPMENT AND MANAGEMENT}

Human resource development underscores the importance of human beings as both contributors and beneficiaries of development. It incorporates all developmental aspects of human beings at every stage of life including occupation and industry development. Human resource management ensures that organization's human resource are utilized and managed effectively. Human resource management is involved in designing and implementing policies and programmes that will enhance human abilities and improve the organization's overall effectiveness. Essentially human resource management deals with the management of human beings in the organization. There are four possible models and strategic approaches in international human resource management.
According to Bernadine (2003), these include the following:

i Ethnocentric model The underlying assumption to this model is that management and human resource practices are critical core competence to a firm's competitive advantage and therefore should not be compromised.

ii Polycentric model This model treats subsidiary as a distinct entity with some level of decision making authority (Onodugo, 2012). The assumption is that international subsidiaries operates in a different environment and conditions separate from that of the parent company and as such should be allowed to evolve its own HR management systems unique to it. Under this model, management and supporting staff are selected therefore cheaper and adaptable to local conditions.

iii Geocentric model It emphasizes integration of its business with the relationship based on collaboration and mutual reciprocity (Onodugo 2012). Staff remunerations are based on individual contributions, global rates and standards.

iv Regiocentric model This is a modification of the geocentric model but regional in scope. Ethnocentric and geocentric models of human resource management increases the chances of technology transfer which maximize the chances of utilizing local labour.

The regiocentric and polycentric models maximize the use of labour and reduce the chances of technology transfer. Accordingly it is better for a country to strategically develop a proper mix between the two goals. 


\section{IV.GLOBALIZATIONS ON HUMAN RESOURCE DEVELOPMENT AND MANAGEMENT}

In India Osagie (2011) is of the opinion that globalization is in non- stop economic process. Therefore individuals, companies and governments are always interested in new processes and innovations. It is therefore necessary to develop workers abilities to meet the global challenge.

The impact of globalization on human resources development in India can be viewed from two perspectives namely:

\section{Organizational and Workplace Learning While} globalization provide opportunity for transfer of existing jobs, know how and wealth from developed countries to new and rapidly developing nations like India, however it is maximized with workplace learning. This ensure job security as well provide platform for socio-economic transformation. Apart from the multinational companies a lot other companies do not put sufficient effort to ensure the growth of their human resources. These ensure that national and competitive advantage, inservice and vocational training for both public and private employees will be necessary for national transformation. The human resources development must include not only economic development but also workplace learning. The success of globalization depends on the utilizing the diverse talents and capabilities of the broadest possible spectrum of human resource. The development and enhancement of the ability of workers required for their job is not only in-dispensable for the security of employment and the improvement of the workers' position but also constitutes the foundation of economic and social development.
2 Knowledge and Technology Transfer One of the factors that have contributed to globalization is technological change, in particular, the information technology. Information technology has been the catalyst for globalization by creating efficient and effective channels to exchange information. (Aziz, 2009). Information technology also provides the communication network that facilities the expansion of products, ideas and resources among nations and people regardless of geographical location. Knowledge and technology provide the current impetus for the present dynamics of globalization. For rapid socio-economic transformation, the information and communication technological capacity of human resource have to be continuously upgraded.

Essentially, globalization is a process of continuous integration of human activities throughout the world. According to Siriwaiprapan (2001), the magnitude and relevance vary from one aspect of human life to another depending on the region, national and local environments.

Globalization has wide the world smaller; with the economies of the world becoming increasingly integrated (Bhagwatty, 2004). Hence the quality, efficiency and competitiveness of human resource management are of utmost importance.

For India, adapting human resource management in term of globalization will have to consider the following according to (Anyim, Ikemefuna and Mbah 2011).

Economic system and level of economic development. ii. Legal system/environment and constraints. iii. Political environment. iv. Educational system and language. v. Sociocultural/ethical environment. 
They further opined that to enhance human resource management in India, the following issues have to be considered among others;

Productivity improvement which is necessary to strengthen the economy in terms of improved quality and greater output. ii. Quality of work life which relates to job satisfaction and commitment. iii. Health and safety at work thereby minimizing accident or injury. iv. Quota system in employment. v. Casualization of labour and outsourcing of services. vi. Labour and social legislations. vii. Labour dissatisfaction at work. viii. Changing values of employees. ix. Economic recession. $x$. Changing roles of government or state in industrial relations. xi. The clean wage options and the social responsibility by the employers.

\section{CONCLUSION}

To resolve the issues that borders in human resources management in India and globalized economy, there is a need for a strategic focus and new capabilities. There is a need to focus on overall outcome rather than staffing or compensation in the organization. Human resource practitioners must therefore co-operate with other managers in the organization. Human resource practitioners in an organization should both focus on employee's welfare and creating value in the organization.

Recommendations Considering the challenges of globalization, human resources development and management should be given topmost priority in India. These could be achieved through the following recommendations: 1 Workers should develop and improve their vocational abilities due to the changes in the economy and society. 2 Promotion of international cooperation in the field of human resource development. 3 Conduction of seminars, workshops, conferences and in-service training for staff to meet the effects of globalization as workplace learning for the development of their human resources. 4 Awarding scholarships especially university students to study overseas in other to receive further workplace training.

\section{REFERENCES}

[1] C.K.Gomathy.(2010),"Cloud Computing: Business Management for Effective Service Oriented Architecture" International Journal of Power Control Signal and Computation (IJPCSC), Volume 1, Issue IV, Oct - Dec 2010, P.No:22-27, ISSN: 0976-268X.

[2] Dr.C K Gomathy, Article: A Study on the recent Advancements in Online Surveying , International Journal of Emerging technologies and Innovative Research ( JETIR ) Volume 5 | Issue 11 | ISSN : 2349-5162, P.No:327-331, Nov-2018

[3] Dr.C.K.Gomathy,C K Hemalatha, Article: A Study On Employee Safety And Health Management International Research Journal Of Engineering And Technology (Irjet)- Volume: 08 Issue: 04 | Apr 2021

[4] Dr.C K Gomathy, Article: A Study on the Effect of Digital Literacy and information Management, IAETSD Journal For Advanced Research In Applied Sciences, Volume 7 Issue 3, P.No-51-57, ISSN NO: 2279-543X,Mar/2018

[5] Dr.C K Gomathy, Article: An Effective Innovation Technology In Enhancing Teaching And Learning Of Knowledge Using Ict Methods, International Journal Of Contemporary Research In Computer Science And Technology (Ijcrcst) E-Issn: 2395-5325 Volume3, Issue 4,P.No-10-13, April '2017

[6] Dr.C K Gomathy, Article: Supply chain-Impact of importance and Technology in Software Release Management, International Journal of Scientific Research in Computer Science Engineering and 
Information Technology ( IJSRCSEIT ) Volume 3 | Issue 6 | ISSN : 2456-3307, P.No:1-4, July-2018.

\section{.AUTHOR'S PROFILE:-}

1.

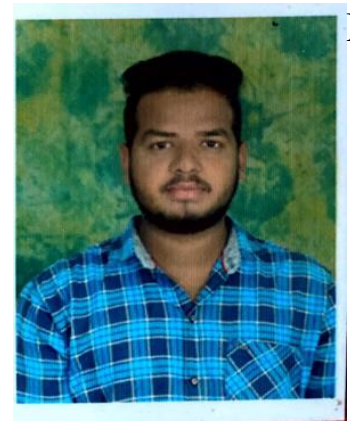

MR. VAMSI.V Student

,B.E in Computer Science and Engineering , Sri Chandrasekharendra Saraswathi Viswa Maha Vidhyalaya, Enathur, Kanchipuram, India. His area of interest in Human Resources Development

2.

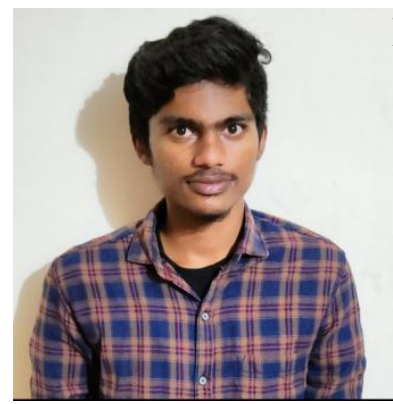

MR.

JEEVAN.Y

Student , B.E in Computer Science and Engineering

, Sri ChandraSekhrendra Saraswathi Viswa MahaVidyalaya Enathur ,Kanchipuram, India. His area of interest in Human Resources Development.
3.

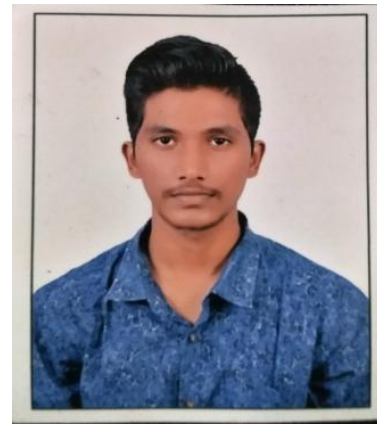

MR.JITIN

PRAGNISH .K Student, B.E in Computer Science and Engineering , Sri Chandrasekharendra Saraswathi Viswa MahaVidyalaya,Enathur, Kanchipuram, India. His area of interest in Human Resources Development.

4.

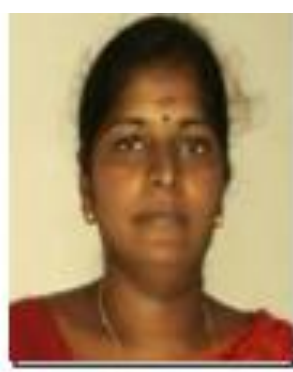

Dr.C.K.Gomathy

is Assistant Professor in Computer Science and Engineering at Sri Chandrasekharendra Saraswathi Viswa

MahaVidyalaya,Enathur,Kanchipuram,India.Her area of interest in Software Engineering,Web Services, Knowledge Management and IOT. 